LIBRI

www.libridergi.org

Kitap Tanıtımı, Eleştiri ve Çeviri Dergisi

Journal of Book Notices, Reviews and Translations

Volume I (2015)

C. OKUYUCU, Divan Edebiyatı Estetiği. İstanbul 2005. L\&M Yayınları, 255 sayfa. ISBN: 9756491442

\section{Serdar DEMIRCAN}

Libri: Kitap Tanıtımı, Eleştiri ve Çeviri Dergisi'nde bulunan içeriklerin tümü kullanıcılara açık, serbestçe/ücretsiz 'açık erişimli' bir dergidir. Kullanıcılar, yayıncıdan ve yazar(lar)dan izin almaksızın, dergideki makaleleri tam metin olarak okuyabilir, indirebilir, dağıtabilir, makalelerin çıktısını alabilir ve kaynak göstererek makalelere bağlantı verebilir.

Libri, uluslararası hakemli elektronik (online) bir dergi olup değerlendirme süreci biten makaleler derginin web sitesinde (www.libridergi.org) yıl boyunca ilgili sayının içinde (Volume I: Ocak-Aralık 2015) yayımlanır. Aralık ayı sonunda ilgili yıla ait sayı tamamlanır.

Dergide yayımlanan eserlerin sorumluluğu yazarlarına aittir.

Künye C. OKUYUCU, Divan Edebiyatı Estetiği. İstanbul 2005. L\&M Yayınları, 255 sayfa. ISBN: 9756491442 Tanıtan: Serdar DEMiRCAN, Libri I (2015) 45-49. DOI: 10.20480/lbr.2015115462

Geliş Tarihi: 14.09.2015

Kabul Tarihi: 22.09.2015

Online Yayın Tarihi: 28.12.2015

URL: http://dx.doi.org/10.20480/lbr.2018115462

Editörya Phaselis Project

www.phaselis.org 


\section{OKUYUCU, Divan Edebiyatı Estetiği. İstanbul 2005. L\&M Yayınları, 255 sayfa.} ISBN: 9756491442

\section{Serdar DEMIRCAN*}

Her ne sanat kim cihanda işlenir Anı halk üstâd elinden öğrenir Aşık Paşa

Prof. Dr. Cihan Okuyucu'nun divanlar üzerine yaptığı çalışmalardan biri olan Divan Edebiyatı Estetiği isimli eseri 2004 yılında L\&M Yayınları tarafından yayımlanmış ve okuyucularla buluşmuştur. Doktora tezini Cinanî, Hayatı, Eserleri, Divanının Tenkitli Metni üzerine yapan Okuyucu, ilerleyen zamanlarda da divan sahibi şahsiyetler üzerine eserler vücuda getirmiş, Divan Edebiyatı Estetiği kitabında ise Divan edebiyatına daha kapsamlı bir bakış açısı sunmuştur. Kitap, Önsöz (XI-XIV), Giriş (3-33) ve üç bölümden oluşmaktadır. Bunlara ilave olarak yer alan Dipnot ve Indeks (249-255) bölümleriyle toplam 255 sayfadan müteşekkildir. Kitabın kapağı yeşil zemin üzerine yerleştirilmiş bir helezon ile tasarlanmıştır.

Önsöz (XI-XIV) kısmında Divan edebiyatını ele alırken onun hayatla ve diğer muhtelif sanatlarla olan karmaşık ilişkilerinin var olduğuna değinilmiş ve kitabın ana bölümlerindeki konu başlıkları verilmek suretiyle değinilecek konulara işaret edilmiştir. Giriş (3-33) kısmında ise sanat dallarındaki farklılıkların sebepleri, Osmanlı İmparatorluğu kurulmadan önceki kültürel atmosfer ile Osmanlı kurulduktan sonraki kültürel ortam ele alınmıştır. Ayrıca Osmanlı́nın kendisinden önce hüküm sürmüş Selçuklu Devleti ve Anadolu Beylikleri Dönemi ile medeniyetler bağlamında kaynaklarla desteklenerek kıyası yapılmış. Divan şiirine vücut veren vasatın tespit edilebilmesi için Osmanlı toplumunun fikrî durumu irdelenmiştir. Bu irdelemeler Osmanlı mimarisi, minyatür sanatı, musikisi, yazı sanatları göz önünde bulundurularak yapılmıştır. Bunlara ilaveten Osmanlı'da hayatın ve sanatın ortak elemanları olan çiçekler ve bahçe kültürü bu eserde yerini almıştır.

Birinci bölümün ilk başlığı Divan Şiirinin Dünyasıdır (47). Bu başlık altında, divan şairinin varlık ve varlık etrafındaki temel kavramlarının ne anlama geldiğinin açıklanacağı belirtilmiştir (53). Ana başlıktaki konu çeşitli alt başlıklara ayrılmak suretiyle derinlemesine ele alınmaya çalışımışır. Buna göre ilk alt başık Tasavvuf ve Varlık Anlayışı (47) kısmında Allah, eşya ve varlık mertebeleri, yaratmanın anlamı, insan, bilgi dereceleri, sanatın gayesine değinilmiştir. Bahsettiğimiz bu bölüm özetle; İsmail Hakkı Bursevîye göre Allah’ın varlık ve birliğine inananlar arasında görülen fikir ayrılıklarının nedenlerinin neler olduğu, mevcudatı meydana getiren yedi mertebenin var olduğu tezi etrafında örülmüştür. Ayrıca Gibb'in, Osmanlı şiir tarihine ait eserinde uzun uzun üzerinde durduğu şairlerin ilham kaynaklarına da yine bu bölümde atıfta bulunulmuştur.

\footnotetext{
* Arş. Gör., Dicle Üniversitesi, Edebiyat Fakültesi, Türk Dili ve Edebiyatı Bölümü, Diyarbakır. serdardemircandicle@gmail.com
} 
Yaratma fiili üzerindeki farklı felsefi bakış açıları İbnü'l-Arabî, Şeyhü'l-Ekber, A. Avni Konuk nazara verilerek örnekler sunulmuştur (59-60). Tasavvuf ve Varlık Anlayışı başlığının Insan (53) alt başlı̆ında ise Livingston'un insana bakışının, Incil ve Kur'an'da insana bakışın nasıl olduğu ele alınmıştır (61). Bilgi derecelerinde mutlak bilginin oluşumu, kesretten kurtulmak isteyen salikin evvela kendini ifna yani yok etmesinin gerekliliği üzerinde durulmuştur (62). Son alt başlık ise Sanatın Gayesidir (61). Burada Burckhardt'a göre sanatın neleri kapsadığının açıklandığı bölüm, A. Nihad Tarlan'ın bir şeyin güzelliğinin Allah'ı yüceltmesine bağlı olduğu ve ilahi bir niteliği yansıttığı oranda güzel olduğu yönündeki cümleleriyle noktalanmıştır (63).

Birinci bölümün bir diğer alt başlığı ise Divan Şiiri Estetiğidir (56). Burada, Divan edebiyatında şiir ve şair anlayışının nasıl olduğu üçüncü derecede alt başlıklarla estetik kavramı da göz önünde bulundurularak ele alınmıştır. Burada öncelikle dönemin şiir anlayışı, şiir ve şaire bakış gibi hususlarda sadece bazı mensur divan ön sözleri ve tezkirelerin giriş kısımlarındaki muhtelif bilgilere tesadüf edildiği vurgulanmıştır. Aşık Çelebi tezkiresinin bu konuya en fazla değinen tezkire olduğu ifade edilmiştir (64-65). Şiire kutsalık atfeden bir şair olan Latifî'ye göre gerçek şairlerin sözleri varidat-ı ilahîdir. Nizami'nin şair ve şiire bakışı: "Sözleri dizen şairler iki alemin hazinelerini nazma çekerler. Hazine kapısının has kilidi şairlerin dili altındadır. Şairler arşın bülbülleridirler, diğer insanlar bunlara nasıl bunlara nasıl benzerler" şeklindedir (66). Ayrıca bu kısımda ilk şiirin ne zaman yazııdığına ilişkin iki rivayete değinilmiştir. Bunlardan birincisi, ilk şiirin $\mathrm{Hz}$. Adem tarafından, öldürülen oğlu Habil için yazıldığıdır. İkincisi ise ilk vezinli eserin yedinci gökteki bir melekten ortaya çıktığıdır. Konunun devamında ise diğer peygamberlerden de şiir söyleyenlerin bulunmasına rağmen şiirin asıl revacını Hz. Peygamber zamanında bulduğu çeşitli örneklerle desteklenerek okuyucuya sunulmuştur (66).

Şairler arasında hoş karşılanmayan şair ve şiirlerin vasıfları beş madde halinde sıralanmıştır. Bunlar: "Toplumun huzur ve düzenini bozucu olmak, şairin kendisini ve toplumu dinî görevlerinden uzaklaştırmak, insanları incitmek, köklü bir bilgi ve ilham kaynağına dayanmamak ve son olarak da şiiri tek amaç, tek meşguliyet olarak almak kendisini bu yolda kapıp koyuvermektir" (67). Bu açıklamalara ek olarak şiir tekniği ile ilgili bazı ortak kabullerde konunun bu bölümünde değinilen hususlardan olmuştur. Mesela nazmı nesirden ayıran şeyin vezin ve kafiye olduğu; kafiyenin de en az iki mısrayı zaruri kıldığıdır. Ancak tezkirecilerin beğenmedikleri şiire manzum mukaffa söz demesinin bu iki özelliği taşıyan her sözün veya nazmın şiir seviyesinde kabul edilmediğini gösterdiğidir. Eserde geçen divan şiiri için söylenmemiş bir anlam bulmanın önemli olduğu ve bu kuralları ve edebî sanatları iyi bilmenin eski şairleri iyi tanımak, dilin inceliklerine vâkıf olmakla mümkün olabileceği şeklindeki tespit dikkate değerdir (69).

Şair anlayışı alt başlığına Latifî’nin Filibeli Fani maddesindeki iyi şair olmak için lüzumlu gördüğü maddeler sıralanarak konuya giriş yapılmıştır. Ayrıca bu kısımda adı geçen şairin müteşairleri şu şekilde sınıflandırdığı görülmektedir: "adi hırsızlar, mana hırsızları, mukallitler, tercümeciler ve manadan mana çıkaranlar" (71).

Divan Şiirinin Dünyası başlığının alt başlığında Klasik Şiirin ve Sanatkârın Özellikleri yer almaktadır. Bu kısım estetik meselesi bağlamında ve ihtiyaç nispetinde diğer güzel sanatlar çeşitli örnekler verilmek suretiyle ele alınmıştır. Bu kısımda ilk olarak şiirin Arapçada "sezmek, bilmek" manalarına geldiği belirtilmiştir (73). Nesre karşı şiiri tercih edenlerin de varlığı yine örneklerle sunulmuştur. Coomarasvamy'ın nazari ve ilhama dayalı sanatların nihai konusunun Allah olduğu düşüncesi ve ilahi kaynaklara temas derecesine göre sanatları sınıflandırması bu bölümde yer 
alan bir başka önemli husustur. Bu sınıflama eserde şu şekilde verilmiştir: "saf aklî ve nazarî sanat, dünyevî ihtiraslar ve duyu organlarıla yaşanan tecrübelerden kaynaklanan dinamik sanat ve son olarak sahte sembol kullanan sahte ve bir şey söylemeyen sanat" (75).

Realite Karşısındaki Tutum (73) başlığı altında, divan şiirinin dış âleme itibar etmediği yönünde eleştirilerin olduğu dile getirilmiş ve minyatür sanatı örneği merkeze konularak eleştirilere yanıt verilmeye çalışımıştır. Ayrıca Fuzuli'nin Gelin ey ehl-i hakikat çıkalım dünyadan / gayr yerler görelim özge safalar sürelim beyti, şairinin ideler âlemine ve reel dünyaya bakışını yansıtması yönüyle örnek olarak sunulmuştur. İlerleyen kısımlarda konu ile alakalı A. N Tarlan'ın, A. H. Tanpınar'ın, Cem Dilçin'in konu ile alakalı görüşlerine yer verilmiştir.

Sanatkârın realite karşısındaki tutumunu belirleyen diğer bir kavram, zât ve sıfatları bakımından hiçbir şeyi Allah'a benzetmemek anlamına gelen tenzihtir. Birçok sanat eleştirmeninin İslam sanatlarını etkileyen en kuvvetli kavram olduğu yönünde ittifak ettikleri tenzih hakkında Prof. Dr. Mehmet Aydın'ın düşünceleri şu şekildedir: "Her dinin, büyük çapta kendi tesiriyle oluşmuş bir kültür çevresinde doğup büyüyen sanatkar üzerinde etkili olması kadar tabiî bir şey olamaz. Din, sanatın hem formuna hem muhtevasına hem de sanat türlerinden bir kısmının ön planda; diğer bir kısmının ise arka planda tutulmasına tesir eder..." (91). Tenzih başlı̆̆ altında değinilen hususlardan biri tasvirin İslam inancındaki yerine değinilmiştir. Tasvir unsurlarından resim ile alakalı Buckhardt'ın şu düşünceleri zikredilmiştir: "Insanda Allah'takine benzer yedi nitelik vardır; görme, işitme, hayat vs. resimde ise bunların hiçbirisi yok, sırf beden vardır. Bu yüzden resim insana bir saygısızılk sayılır. Hadiste Allah'ın yarattıklarını taklit eden sanatkârlar suçlanır. Ancak minyatürdeki gibi canlı intibaı vermeyen şekliyle resim var olabilmiştir" (93).

Modern sanat hareketlerinde estetik ve fayda kavramlarının birbirinden ayrı düşünüldüğü, bütüncü bir hakikat anlayışına sahip olan İslam'da ise güzel ile faydalının; bilim ile sanatın birbirinden ayrılmaz olduğu kitabın Ilim ve Sanat/ Güzel ve Fayda (89) başlığı altında ele alınmıştır. Aynı başlık altında Seyyid Hüseyin Nasrıın şiiri hakikati ifade etmenin bir başka yolu olarak gördüğü ve onu mantığa benzettiği; ancak onun saf mantıkla ulaşılamayan yönlerinin olduğu yönündeki tespitlerine değinilmiştir (96-97).

Klasik şiirin özellikleri yukarıda verilen başlıklar altında ele alındıktan sonra klasik sanatkârın özellikleri de aynı şekilde alt başlıklar halinde ele verilmiştir. Konu ile alakalı ilk alt başlık Sanatta Ferdiyettir (101). Bu başlıkta ilk olarak Beşir Ayvazoğlu'nun Doğu ve Batı sanatçılarını açıklarken kullandığı tiplemeler ve bunların ne anlam ifade ettiğidir (108-109). İlerleyen kısımlarda ise Berna Moran, Gölpınarlı, Tanpınar, Nihat Tarlan gibi isimlerin bu konu üzerine düşünceleri nakledilmiştir.

Klasik şairlerimizin batılı meslektaşlarından ayrıldığı temel noktalardan birisinin de bilgi kaynağı hakkındaki tasavvurları olduğu öne sürülmüştür. "Rönesans, gerçeklik kavramını akıl ve duyular dünyası ile sınırlayan ve bu özelliğiyle eskiden kopan bir dönemi temsil eder. Oysa Gazali'ye göre duyular ve akıl bizi gerçeğe götüremez. Zira akıl varlığı bölerek idrak eder, oysa marifet varlığın birliğini kavramak, zıtıklardan kurtulmaktır" (115-115). Bu düşüncelerin yanında Klasik edebiyatımızda aşka mani olması bakımından aklın bir ayak bağı olarak görülmüştür. Neredeyse bütün şairlerimizde cünûn (delilik) halinin takdis edilmesi, Mecnun'un ideal bir tip olarak benimsenmesi de bu telakkiyle ilgili görülmüştür (117-118).

Birinci bölümün en son kısmında kutsal sanatta sanatçı ve kurallara yer verilmiştir. Konuya 
klasik şiirimizin bariz özelliğinin geleneksel ve kuralcı olduğu ifade edilerek başlanmıştır. Burckhardt'ın "Dinî sanat, zarurî olarak kuralcıdır, zira gelenekten maksat ilahî kanunlara tâbi olmaktır" (112) sözü de ilk cümleyi destekleyici mahiyette ele alınmıştır. Burckhardt'ın ifadelerini ardından Livingston'un konu ile alakalı Geleneksel Edebiyat Teorisi ismindeki eserde geçen şu tespitler vardır: "Dinde her beyan tarzı makbul sayılmaz, bazı sabit kurallar vardır. Insanlar da klasik toplarda dinin ve toplumun çizdiği sınırlar içinde hareket ederler. Ancak geleneğin içindeki hareket bir müddet sonra alışkanlığı ve ardından da daha az farkındalığı beraberinde getirir. Böylece bu kaideleri kendisinin ikinci fıtratı haline getiren şair bir otomat olarak onlara uymaya başlar" şeklindeki yorumuna yer verilmiştir (118-119).

Kitabın ikinci bölümüne Divan edebiyatı hakkında genel bilgiler verilerek başlanmıştır (121). Burada ilk olarak divan edebiyatının tarifi ve isimlendirme işlemi yapılmış ve Divan edebiyatı dönemlere ayrıldıktan sonra bu edebiyatın ortaya çıkışı ve Türkçeye bakışııın nasıl olduğu ifade edilmiştir (121-128). Bu bölümün beşinci alt başlığı En Eski Türkçe Divanlardır (122). Bu kısımda edebiyatımızda divan tertibinin Arap geleneğine bağlı olduğu dile getirilmiş ve bu sebeple konuya Arap edebiyatında "divan"ın geçmişi hakkında genel bilgiler verilerek girilmiştir. Daha sonra bu geleneğin Anadolu'ya taşınması süreci ve bugün elde bulunan kaynakların kaynağı belirtilmiştir (128-130).

Divan şiiri geleneğinde hemen her şairin gerçek isimlerinden başka şiirde kullandıkları isim olan mahlas konusuna girilmiştir. Mahlasların hangi hususlar göz önüne alınarak edinildiği de maddeler halinde ele alınmıştır (130-131). Divan şiirinde sıklıkla kullanılan sözcükler ve bunların Türkçe karşılıkları bir tablo haline getirilip sınıflaması yapılmıştır (139-146). Nazmın yanında nesir tarzı ile ilgili de bazı anekdotlar kitapta yerini almıştır. Bu kısımda Anadolu'da nesir tarzının gelişimi hakkında bilgiler verilip mensur eser çeşitleri kısa olarak açıklanmıştır (146-151).

Divan edebiyatı hakkında genel bilgiler alt başıklar halinde verildikten sonra Osmanlı toplumunda şiir ve şair konusu da aynı şekilde alt başlıklar halinde ele alınmıştır. Bu kısımdaki alt başlıklar şu şekildedir:

1. Osmanlı Toplumunda Meslek Olarak Şairlik (151-153)

2. Şiirin Takdim Şekli (153-154)

3. Şiir Mahfilleri ve Adabı (154-158)

4. Divan Şairlerinin Coğrafi ve Meslekî Dağılımı (158-159)

5. Şairler Hakkında Bilgi Veren Biyografik Kaynaklar ve Bilgi Değerleri (159-162)

ikinci bölüm biterken değinilen son konu Divan şiiri şekil Özellikleri ve Nazım Şekilleri (158) olmuştur. Bu başlık altındaki üçüncü derecedeki alt başlıklarda aruz, kafiye sistemi, redif, nazım şekilleri tanıtılmış ve çeşitli örneklerle pekiştirilmeye çalışılmıştır (162-185).

Kitabın üçüncü yani son bölümünün ana başlığı Geleneğin Muhteva Dünyasıdır (185). Bu ana başlığın altında işlenen ilk konu "Divan Şiirinin Fikir Kaynakları"dır (185). Bu kaynaklar da şöyle sıralanmıştır:

1. Ortak İslam Kültürü

2. Acem Esatiri

3. Mahalli Unsurlar

Yukarıda sayılan kaynakların hangi kaynaklardan beslendiği de bir alt başlıkta sıralanmış ve kısa 
açıklamalarla okuyucuya şu şekilde sunulmuştur:

Illk alt başlık Dini-Tasavvufî-Tarihî ve Efsanevî Kaynaklardır (185). Bu alt başlıkta tasavvufun Klasik şiir için önemi, peygamber kıssaları, veli menkıbeleri ile tarihi ve efsanevî şahsiyetlere ait hikâyeler, efsane ve rivayetler, batıl ilimler yer almaktadır. 1.2 başlığında Şehname Kahramanları (191) ve son olarak da 1.3 de Yerli Malzemeler (192) belirtilmiştir. Geleneğin Muhteva Dünyası ana başlığının altındaki bir diğer başlık Divan Şiirinin Felsefesidir (193). Bu alt başlıkta divan şirinin malzemesi ve ilham kaynağının büyük ölçüde dinî unsurlardan oluştuğu ve bu sebeple divan şairinin de buna uygun bir hayat felsefesine sahip olduğuna değinilmiştir.

Divan Şiirinin Başlıca Konusu Olarak Aşk (194-216)ana başlığı altında,

1. Şiirimizde Aşkın Yeri

2. Şairliğin Şartı Olarak Aşk

3. Arzu ve Aşk

4. İslam Kültüründe Aşk Anlayışının tekamülü; Cinsel Arzudan Ulvî Aşka

5. Aşk, Âşık ve Maşukla illgili Sembolik Kavramların Oluşumu

6. Standart Sevgili Tipi ve Standart Duygular

7. Sevgilinin Fizikî Özellikleri ve Kaynağı

8. Öldürücü Sevgili Tipi ve Bu Tipin Kaynağı

9. Sevgilinin Cinsiyeti ve Oğlan Aşkının Toplumsal Kaynağı

Üçüncü bölümün son alt başlığı Divan Edebiyatı Etrafındaki Tartışmalardır (220). Bu başlık altında Eski Şiirin muhtevasına yönelik tenkitler maddeler halinde sıralanmıştır. Bu maddeler şunlardır:

1. Hayal Dünyası gerçekle ilgili değildir.

2. Konular Beşerî his ve fikirleri yansıtmaz.

3. Toplum Meselelerine yabancıdır.

4. Sıkı, kuralcı ve mazmuncudur.

5. Başlangııından bitimine kadar hep aynı kalmıştır.

6. Samimi Değildir, caize edebiyatıdır

7. Ahlaken düşüktür.

8. Dini ve dar bir edebiyattır.

Yukarıda sayılan bu maddeler dışında Divan edebiyatını Millilik-Gayrimillîlik, taklitçilik, yüksek zümre edebiyatı olduğu ve Tanzimat şiirinin dil bakımından elektik bir yapı arz ettiği ve gayrimillî olduğu ve samimiyetsiz olduğu şeklinde eleştirenler olmuştur.

\section{Sonuç}

Cihan Okuyucu'nun hazırlamış olduğu bu çalışma, Divan Edebiyatı araştırıcıları için başucu kitabı niteliği taşımaktadır. Ayrıca eser, klasik metinleri estetik bağlamında değerlendirirken başvurulacak yöntemlerin öğretilmesi yolundaki önemli bir boşluğu dolduracağı ve bu alanda öğrenim gören, alana ilgi duyan herkes tarafından okunmasının faydalı olacağı kanaatindeyiz. 